\title{
Women's Education, Family Planning, or Both? Application of Multistate Demographic Projections in India
}

\author{
Leiwen Jiang ${ }^{1}$ and Karen Hardee ${ }^{2}$ \\ ${ }^{1}$ National Center for Atmospheric Research, 1850 Table Mesa Drive, Boulder, CO 80305, USA \\ ${ }^{2}$ Population Council, One Dag Hammarskjold Plaza, 9th Floor, New York, NY 10017, USA \\ Correspondence should be addressed to Leiwen Jiang; ljiang@ucar.edu
}

Received 22 August 2013; Revised 8 December 2013; Accepted 12 December 2013; Published 9 January 2014

Academic Editor: Sidney R. Schuler

Copyright ( 2014 L. Jiang and K. Hardee. This is an open access article distributed under the Creative Commons Attribution License, which permits unrestricted use, distribution, and reproduction in any medium, provided the original work is properly cited.

Is education the best contraceptive? Using the multistate human capital projection model, our analysis shows that the projected changes in India population vary depending on investments in education and helping women reduce unwanted fertility rates, that investments in both education and helping women in each education category-but particularly less educated women-meet their wanted fertility will have the largest impacts on Indias population projections, and that the impact from investment in reducing unwanted fertility will be much more immediate and significant than only investments in education. Our analysis also reveals that an increasing education transition rate in India will not only help to achieve a population age structure that is favorable for economic growth, but also result in a larger share of skilled labor force that help to achieve higher economic growth rate. More importantly, investment in girls' education and achieving gender equality in education will be the most effective measure to increase India's population education level and improve its overall values of human capital.

\section{Introduction}

Education confers a range of benefits to individuals and societies. Hannum and Buchman [1, Page 20] find that "countries with better-educated citizens tend to have healthier population, as educated individuals make more informed health choices, live longer, and have healthier children. In addition, the populations of countries with more educated citizens tend to grow more slowly, as educated people are able to lower their fertility." Cohen et al. [2] and Rehani [3] also cite a range of benefits of secondary education in the developing world, including lowering fertility and population growth. Education affects a range of factors associated with the socioeconomic development of women, including fertility, health, and economic achievement $[4,5]$.

Female education, particularly completion of primary school and into secondary school, has emerged as strongly related to lowered fertility [6-12]. In a study of the spread of primary schooling in sub-Saharan Africa, Lloyd et al.
[13, Page 510] used contraceptive practice as a marker of the fertility transition and found that "all countries that have achieved mass schooling also show evidence of having entered the fertility transition." Only two countries in their study started the transition prior to mass education. While variations have been found, for example, by Cochrane [14], that small amounts of education can result in higher levels of fertility, leading to an inverted $U$ shape relationship, and that the relationship varies across countries and within educational groups [15]; generally, higher levels of education are associated with lower levels of fertility, to the point that Carr [16] asked if education is the best contraceptive?

And yet, even educated women need to use a means of fertility control to avoid unintended pregnancies. Using data from 26 DHS, Martin [9] assessed the relationship between female education and wanted fertility and found that more highly educated women did tend to have lower fertility desires, but that "[U]nequal implementation of fertility goals by means of contraceptive use appears to be a major factor 
behind observed differentials" (p. 194). Contraceptive use was higher among more highly educated women in all 26 countries. In an assessment of wanted and unwanted fertility in six countries at various stages of the fertility transition, Bongaarts [11] found a general trend that unwanted fertility is lowest among women with higher levels of education, although he added, parenthetically, that "(unwanted fertility among women with no schooling is still much lower than it would have been in the absence of birth control)" (p. 331).

Drèze and Murthi [17] found that female literacy affected fertility in India, yet, while they decompose the effect of female education on fertility into three effects, including women's ability to achieve planned number of births, they do not include that in their analysis. Also in India, Moursund and Kravdal [18] found that individual level and community level education both affect the probability that a woman was using contraception. Interestingly, their model also found that the probability of using contraception also increased if a primary health center or dispensary were in the village or $0-5$ kilometers, compared to the reference group of $5+$ kilometers. While they did not discuss this result, presumably, women received family planning services from these sites. Diamond et al. [10], analyzing data from 31 countries, found that the strength of the family planning program affects the relationship between education and fertility. In countries with a moderate to strong family planning program, modest levels of education were associated with substantially lower fertility, whereas in countries with weak or nonexistent family planning programs, fertility rates of women with a few years of education were often found to be higher than that of women with no education.

Axinn and Barber [19] assessed the proximity to school, to a health center for family planning services, and regular bus routes in rural Nepal to measure the relationship between mass education and fertility limitation. They found that schools spread before health centers and bus routes. They posit that access to education drives the desire to limit fertility and the demand for access to contraception. "In this type of setting, it appears that access to family planning programs may not be enough...mass education can have a substantial impact on fertility-limiting behavior in addition to improving access to health care and family planning services" (p. 501). Caldwell et al. [20, Page 47], in ethnographic research in rural South India on the educational transition, found that "In our large village over half of all sons have received some schooling for half a century. Why then, did fertility not fall sooner? Most of the population offer a simple answer: there was no way, the family planning program did not exist earlier." In other words, both education and access to the means to control fertility are important for helping women meet their fertility desires. Access to the means of controlling fertility also makes an important contribution to empowerment of women [21, 22].

Using data from India, this paper seeks to answer the questions: what could female education contribute to future changes in the population? What will achieving wanted fertility contribute? What will combined efforts to promote female education and achieve wanted fertility contribute?

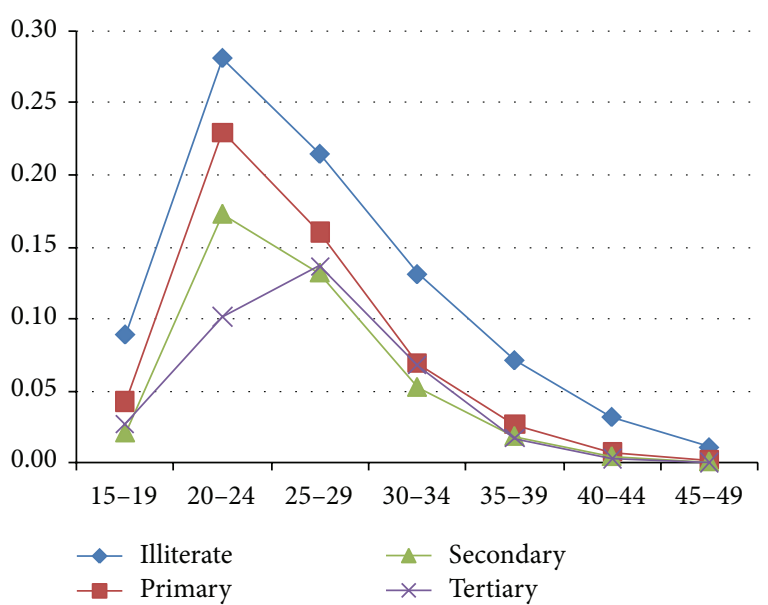

FIGURE 1: Age-specific fertility rate of Indian women by education.

\section{Methods and Data}

Analysis for this paper is conducted using a multistate demographic method with a focus on education, which is developed at International Institute for Applied Systems Analysis (IIASA), in collaboration with the Vienna Institute of Demographic Research [23, 24]. We make projection to 2051 the changes in India population by age, sex, and category of educational attainment, under potential six scenarios that include two different educational attainment trends, reducing unwanted fertility, and combinations of the educational trends and unwanted fertility, compared to a constant scenario. Two scenarios also included changes in mortality to give a more complete picture of population dynamics for India’s future.

To prepare the input data for the model simulation, we derive baseline population by single year of age, sex, and education attainment using the data from the India 2001 census. The age-specific fertility rates for population by education categories are also based on the same data source. Figure 1 shows that the age-specific fertility rates of India women differ substantially by education categories. The higher the education attainment, the lower the fertility rate: 4.1 births for women with no education, 2.7 births for women with primary education, 2 births for women with secondary education, and 1.8 births for women with tertiary education.

As the data from the 2001 Census on mortality is not distinguished by education levels, we derive age-specific survival ratio by education based on the findings from research in other countries that the life expectancy at age 15 of those with no education is one year smaller than those with primary education; the differences between primary education and secondary and between secondary and tertiary are all two years each, resulting in a five-year difference between the highest and lowest categories [25]. Based on research from other countries and sensitivity analyses using our projection model, we derived life expectancies at birth for the Indian population by educational categories for the base year (2001) so that the combined life expectancy of all those categories is consistent with life expectancy of the total population. 
TABLE 1: Wanted fertility rate of Indian women of childbearing ages, from national family health surveys.

\begin{tabular}{lcccccr}
\hline & \multicolumn{3}{c}{$2005-2006$ NFHS } & \multicolumn{3}{c}{ 1992-1993 NFHS } \\
& Wanted TFR & TFR & Ratio & Wanted TFR & TFR & Ratio \\
\hline & $(1)$ & $(2)$ & $(1) /(2)$ & $(1)$ & $(2)$ & $(1) /(2)$ \\
No education & 2.4 & 3.6 & 0.667 & 3.2 & 4 & 0.800 \\
Primary & 1.9 & 2.6 & 0.731 & 2.3 & 3 & 0.767 \\
Secondary or higher & 1.7 & 2.1 & 0.810 & 1.9 & 2.4 & 0.792 \\
Missing & 1.1 & 1.1 & 1.000 & 3.1 & 4.1 & 0.756 \\
\hline Total & 1.9 & 2.7 & 0.704 & 2.6 & 3.4 & 0.765 \\
\hline
\end{tabular}

Among the female population, life expectancy by educational category is 63.7 for no education, 64.7 for primary education, 66.7 for secondary education, and 68.7 for tertiary education.

To derive the age-specific education transition rates, we use the proportion of population by education attainment by sex and age in the 2001 Census, assuming that the increase in the proportion of each education level represents the upward transition across ages, and calculate the increase of education attainment and the conditional transition probability to achieve this increase. Based on the derived agespecific educational transition rate, the overall conditional education transition rates of the male population are 0.85 for transferring from no education to primary education, 0.63 for primary education to secondary education, and 0.26 for secondary education to tertiary education. The corresponding figures for the female population are 0.79 , 0.54 , and 0.24 , respectively.

We construct six scenarios of future changes of the Indian population in order to analyze: (1) the impacts of investment in education on overall population growth; and (2) the potential impacts of investment in reducing unwanted fertility relative to the impact of investment in education, on population growth. The scenarios described below include (1) Constant, (2) Global Education Trend, (3) Fast Track Educational Attainment, (4) Reduce Unwanted Fertility, (5) Reduce Unwanted Fertility/Global Education Trend, and (6) Reduce Unwanted Fertility/Fast Track Educational Attainment.

First, as the baseline Constant Scenario, we assume that the fertility, mortality, and education transition rates from the baseline of year 2001 would remain constant for the whole projection period to 2051.

Second, using the same values for fertility and mortality by educational category as in the Constant Scenario, we assume a moderate increase of the educational transition rate which is embedded in the Global Education Trend (GET) Scenario [24], which assumes a country's educational expansion will follow an expansion trajectory based on the historical global trend. Under this assumption, for India, the overall conditional transition rates by year 2051 will increase to 0.99 for no education to primary education, 0.98 for primary education to secondary education, and 0.3 for secondary education to tertiary education, for both men and women. The assumed transition rates in the year 2051 are similar to the present level of the United States.

Third, we assume a Fast Track Educational Attainment (FT) Scenario in which India will follow the best national practices in education achievement in world history and achieve an overall transition rate of 0.99 for no education to primary education by year 2016, 0.98 for primary education to secondary education by 2031 , and 0.6 for secondary to tertiary education by 2051. Similar to the Global Education Trend Scenario, the Fast Track Educational Attainment Scenario only changes the education transition rates compared to the Constant Scenario.

In the fourth Reduce Unwanted Fertility (RTFR) Scenario, compared to the Constant Scenario, we only change the total fertility rate (TFR). The total fertility rate of a population can be decomposed into wanted and unwanted fertility based on household surveys that ask women the number of children they desire. Unwanted fertility is an important concept because, in principle, it can be reduced in part by ensuing access to family planning services that assist couples in achieving their desired family size. Moreover, the estimates of unwanted fertility often serve as an input to population projections, by indicating the future trend in fertility and the scope for fertility to fall through population policies and effective reproductive health services [26-28].

In our analysis, the assumptions about the changes in fertility are based on the proportion of the wanted fertility rate relative to the observed total fertility rate derived from India's 1992-93 and 2005-06 National Family Health Surveys (http://www.nfhsindia.org/). As shown in Table 1, about 24 to 30 percent of the births to Indian women are considered unwanted. While the proportion of unwanted fertility for women with education did not change much between the 1992-93 and 2005-06 surveys, the proportion for uneducated women increased significantly, indicating the gaps between declining desired family size and the ability of uneducated women to achieve their desired family size, including accessing family planning services. In this scenario, we assume that the TFRs of women in each education category will gradually decline and reach the levels of wanted fertility (as measured in years 2005-06) by year 2021, and remain constant afterwards. This is not an implausible scenario. A test of this scenario shows that India's total fertility rate declines from above three to below replacement level (2.0) by year 2021, which falls in between the medium (2.25) and low (1.75) fertility variant of the UN World Population Prospects 2012 Revision [29].

In the previous scenarios, mortality of the population by education is assumed to remain the same over the whole projection period in order to test the net impacts of education and fertility change (family planning services) on population 
growth and labor force (human capital) changes. In the fifth scenario, the Reduce Unwanted Fertility/Global Education Trend (RTFR-GET) Scenario, we assume that fertility changes will be the same as described in the RTFR Scenario, and that the education transition rate follows Global Education Trend Scenario. We also consider a more complete picture of population dynamics for India's future, by taking into account the impacts of changes in mortality in addition to fertility and educational transition. We adopt the assumption about life expectancy from the UN population projection 2012 Revision [29].

Finally, the sixth scenario, the Reduce Unwanted Fertility/Fast Track Educational Attainment (RTFR-FT) Scenario, included the same parameters as the previous scenario, except that the education transition rate assumed the rate of the Fast Track Educational Attainment Scenario. By comparing the results from the fifth and sixth scenario, we can assess the combined effects of educational investment on births and deaths and consequently on population size and composition changes.

\section{Results}

3.1. Population Growth. While India's population will continue to grow under all scenarios, the population growth rate will be the highest under the Constant Scenario in which total population size will reach about 1.8 billion by the middle of the century (Figure 2). Under the Constant Scenario, even as the TFRs of women of each education category stay the same, the national TFR will decline from 3.05 in 2001 to 2.68 by 2051 . This is because women in the older generations with lower levels of education but higher TFRs increasingly leave the childbearing age group, while younger generations who are relatively more educated and have lower TFRs increasingly enter childbearing age.

Projection results show that when the education transition rate increases-under the Global Education Trend (GET) and Fast Track Educational Attainment (FT) Scenarios, India's population growth rate declines. This is mainly due to the fact that having more educated women in the population drives down the national total fertility rate: under GET and FT Scenarios, the TFR would decline to 2.2 and 1.97 by year 2051, which is 0.5 and 0.7 lower than that under the Constant Scenario. Although increases in education will also reduce mortality as people with higher levels of education have higher life expectancy, the multiplicative effect of declining fertility over generations will result in a much more significant reduction in total population growth. Total population size will be about 100 million and 160 million smaller, respectively, than that under the Constant Scenario. Therefore, investment in education, particularly girls' education, does contribute to slower population growth, even though slower population growth is not the goal of investing in girls' education.

We also test how reducing unwanted fertility will affect population growth in India through the RTFR Scenario. Other factors being equal, if Indian women in each education category gradually reduce fertility to reach the level

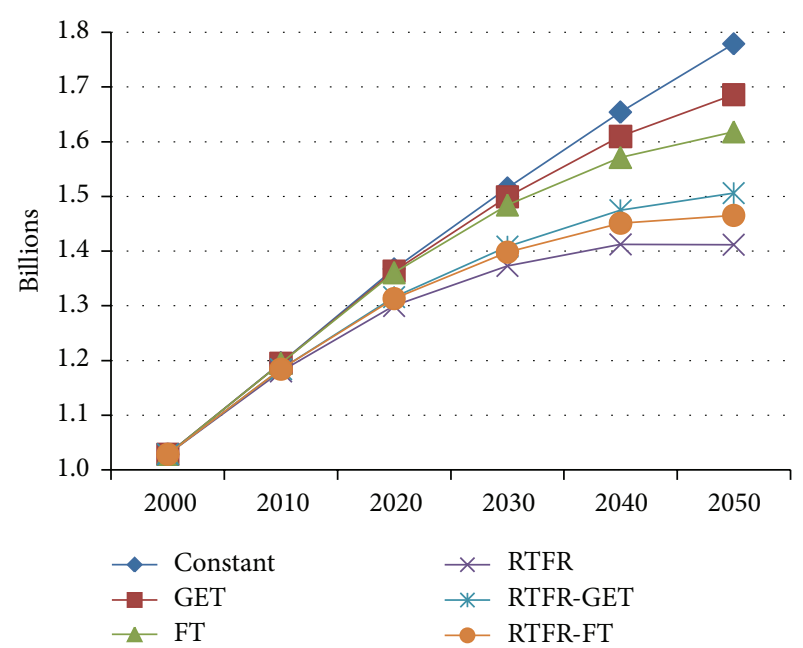

Figure 2: Indian Population Change. Key: Constant $=$ Constant Scenario; GET = Global Education Trend Scenario; FT $=$ Fast Track Educational Attainment Scenario; RTFR = Reduce Unwanted Fertility Scenario; RTFR-GET = Reduce Unwanted Fertility/Global Education Trend Scenario; RTFR-FT = Reduce Unwanted Fertility/Fast Track Educational Attainment Scenario.

of their wanted fertility of today by 2021 , the result will be overall declines in the total fertility rate from 3.05 to under replacement level by 2021, and further to 1.97 by 2031, due to the aging out of less educated women from the reproductive ages. Under this scenario, India's population would be 50 million less by year 2021 and 260 million less by year 2051, relative to that under the Constant Scenario. Comparing the effects on population growth under the GET, FT, and RTFR scenarios, the impact from investment in helping women reach their desired fertility, including through increasing access to family planning program and reproductive health services, will be much more immediate and significant than only investments in education. This is mainly because investment in education takes a number of years to have an effect on fertility reduction when more educated girls gradually reach childbearing age. Given the nature of reproductivity of fertility over generations, the impacts of postponing reduction in fertility by investment in education will be amplified overtime. Therefore strengthening family planning and reproductive health services, particularly for less educated women who are less likely than more educated women to be using contraceptive at rates to achieve their desired fertility, and promoting contraceptive use among this group are important compliments to expanding education for girls.

Another reason that population growth under GET and FT scenarios is higher than under the RTFR scenario is because increasing the education transition rate reduces the mortality rate and, as described above, life expectancy is higher among more educated people. Although no changes in life expectancy of the population by education are assumed for future years in all three scenarios, increasing the education transition rate increases the proportion of the population with higher education levels and drives the life expectancy 
of the overall population by 0.3 and 0.5 years longer by 2051 under the GET and FT Scenarios than under RTFR Scenarios.

Moreover, the impact of an increasing education transition rate on life expectancy of the overall population is slightly underestimated. The GET and FT Scenarios only consider the disparities in life expectancy among people of various education levels, due to improving socioeconomic status, better knowledge about medicine and health, adaption of healthier life styles and sanitation habits, safer working environment, and so forth. However, indirect impacts of higher levels of education on life expectancy, such as better knowledge to raise healthier children and higher motivation to improve community sanitation and health facilities, are not considered. However, there is limited research that could provide evidence on how much improving education reduces mortality rates, making it difficult to build into scenarios of changes in life expectancies.

The impact of the changes in education and fertility on population growth through deaths is complicated. While an increase in education increases life expectancy of the overall population and reduces mortality as descried above, declining fertility through reducing the unwanted fertility or changing the composition of the population by education category will change the population age structure and result in population aging. A more mature or aged population will increase population death rates due to a larger proportion of elderly population, even though mortality rates remain the same or even increase. For instance, the population death rate by year 2051 is 14.4 per thousand under the RTFR Scenario, significantly higher than under the Constant Scenario (12.5\%o), although the life expectancy is the same. The population death rates by year 2051 under GET and FT Scenarios are 12.7 per thousand and 12.9 per thousand, respectively, also higher than under the Constant Scenario, even though the life expectancies under FT and GET Scenarios are 0.3 and 0.5 year longer.

3.2. Labor Force. As the population of India increases, the total number and the proportion of the population in the labor force will also increase in the coming decades under all scenarios (Figure 3). This increase in the labor force population provides India with the potential to capitalize on the demographic dividend, in which a large proportion of the population being in the age groups participating in the labor force may contribute to a high economic growth rate and economic takeoff, as long as there is an enabling environment supporting economic growth [30, 31].

However, the proportion of the population of labor force age is quite different under the various scenarios. In general, the lower the total fertility rate, the higher the proportion of the population of labor force age. Under the Constant Scenario, the proportion of the population of labor force age will increase from 50 percent of the total population of India in 2001 to about 57 percent by 2021, where it will stay until it slightly declines after 2041. Under the increasing education transition rate in the GET and FT Scenarios, the proportion of the population of labor force age will be virtually the same as under the Constant Scenario until 2021 and will increase to reach 59 percent and 61 percent, respectively, by the year 2051 .

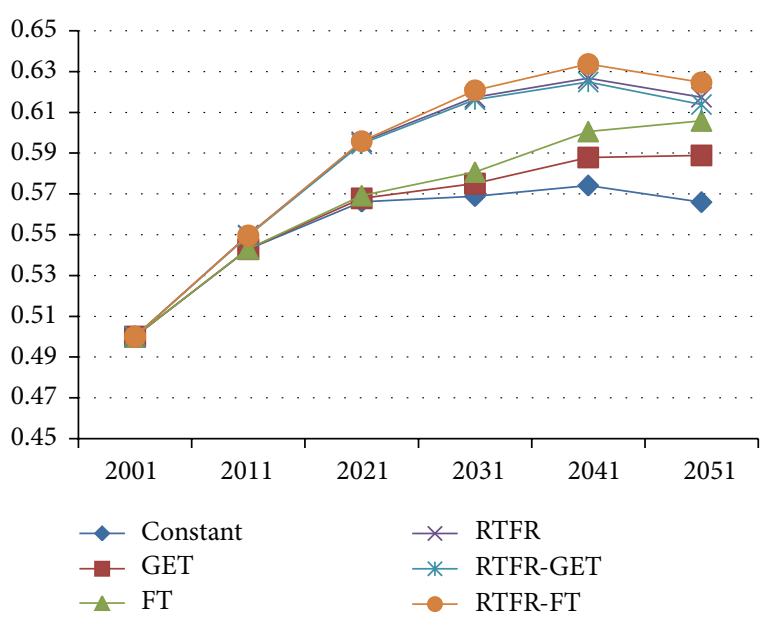

FIgURE 3: Changes in proportion of labor force population.

The increase in the proportion of the population of labor force age is much more substantial under the scenarios of reducing unwanted fertility. Through reducing fertility to the level of today's wanted fertility by the year 2021, the proportion of population in the labor force under the RTFR Scenario will quickly increase to above 59 percent by the year 2021 and will hit a peak of about 63 percent by the year 2041. This proportion will be nearly the same under the Reduce Unwanted Fertility/Global Education Transition Scenario, although it has higher life expectancy and education transition rate. This again shows the importance of fertility levels on not only total population size but also the population age composition. The Reduce Unwanted Fertility/Fast Track Educational Attainment Scenario will also significantly drive the proportion of population in the labor force up in future years.

3.3. Education Composition. While an increasing proportion of the population of labor force age offers the potential of the demographic dividend, according to experience in other regions of the world, such as countries in East Asia, it will be important for the labor force to be educated. According to the 2001 Census, more than 41 percent of the Indian labor force population was illiterate (not shown in a table). Under the Constant Scenario, this proportion will gradually decline to about 26 percent by 2021, and 18 percent by 2051, as older, illiterate generations leave the labor force. The proportion of the labor force with tertiary education will increase only slightly from 13.5 percent in 2001 to 14 percent by 2021, but will decrease to 12 by 2051 . In particular, the education level of the female labor force is extremely low: in 2001, about 54 percent of the female population of labor force age was illiterate and only 9 percent had tertiary education. Under the Constant Scenario, the situation will not improve very much. If India follows the Global Education Trend, the proportion of the population of labor force age with secondary or tertiary education, who account for the majority of the skilled labor force will increase from 34 percent in year 2001 to 69 percent by 2051 (Figure 4). Under the Fast Track 


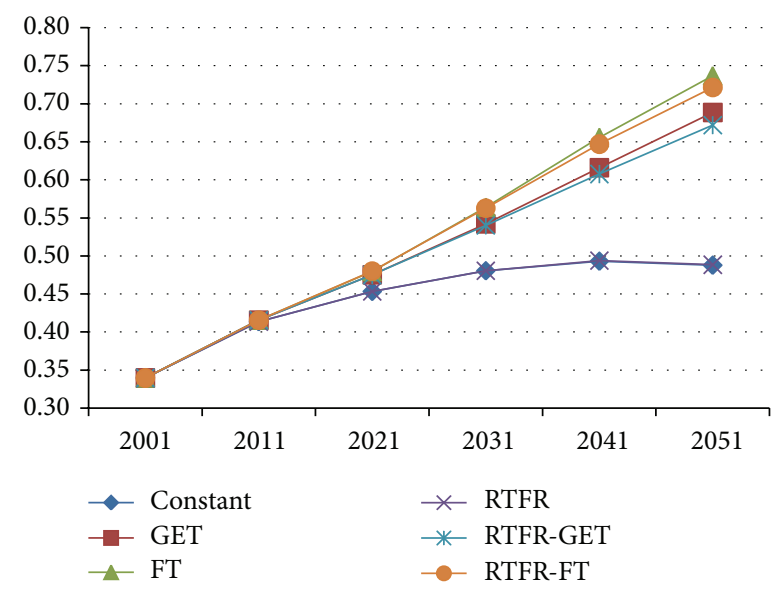

FIgURE 4: Changes in proportion of labor force population with secondary or higher education.

Educational Scenario, the proportion will increase to about 74 percent by year 2051. The major increase is due to the improving educational attainment of women of labor force age, which will increase from 23 percent in 2001 to more than 70 percent by 2051 and, as under the GET scenario, both men and women will achieve universal secondary education, and the tertiary education transition rate rises to 60 percent.

The projection results also show that, although the proportion of the population of labor force age increases very fast by achieving replacement fertility rate under RTFR Scenario by 2021, without increasing investment in education, the percentage of labor force population with secondary or tertiary education levels remains lower than 50 percent in the future decades, which will affect India's ability to benefit from the demographic dividend.

The projection result under the RTFR-GET Scenario offers a possible future. Under this scenario, the proportion of the population of labor force age with secondary and tertiary education will increase from 34 percent in 2001 to 45 percent in 2021 and 67 percent in 2051. These projections are slightly lower than those under the GET Scenario because of higher life expectancy in that scenario that retains more less educated people in the population of labor force age from the older generation. The RTFR-GET and the RTFR-FT Scenarios again produce significantly higher proportions of the population of labor force age with secondary and tertiary education.

Population pyramids provide a convenient tool to display and summarize the changes in population size and composition. Here we present a set of population pyramids in which the changes in total population size, age, sex, and educational attainment under two of the scenarios (Figures 6 and 7) and the Constant Scenario (Figure 5) for the years 2001, 2021 and 2051 are displayed. Under all scenarios, while India's total population will expand in the future, changes in population age structure are apparent, with a lower fertility rate and higher life expectancy, and the larger share of population in the middle and old age groups. For instance, the share of middle age and old population under the RTFR-FT
Scenario is the largest-much larger than that under the Constant Scenario. From the population pyramids, one can also observe the changes in the education composition of the Indian population over time. For example, the large illiterate population, particularly the illiterate female population ages $20-45$ in 2001, moves up with age over time and gradually leaves the population through mortality, particularly due to the lower life expectancy of less educated populations than those with higher education levels. Under the Constant Scenario, although the population size of labor force age in 2021 and 2051 will increase the most, the majority of the labor force population has only primary or no education. In contrast, under the RTFR-FT Scenario, the population of labor force age will be comparatively small. However, a large share of the labor force has tertiary education, and virtually none of the population of labor force age under 40 will be illiterate by 2051 owing to the universal primary education. Moreover, the skewed distribution between males and females of the population by education will disappear in 2051 under this scenario.

\section{Discussion}

Using the multistate demographic projection model and based on the data from India's 2001 Population Census, our analysis shows that India's future population change will vary depending on investments in education and helping women reduce unwanted fertility rates.

Investments in both education and helping women in each education category-but particularly less educated women-meet their wanted fertility will have the largest impacts on India's population projections. Comparing results from the various scenarios, the impact from investment in meeting wanted fertility, including through renewed focus on improving access to family planning program and reproductive health services and removing other barriers to contraceptive use, will be much more immediate and significant than only investments in education. Holding other factors constant, expanding programs to help Indian women in each education category gradually achieve their wanted fertility rate of today by the year 2021 will result in the overall total fertility rate declining from 3.05 to under replacement level (defined as 2.1 children per couple) by year 2021, and further to 1.97 by year 2031. Under this scenario, India's population will be 260 million less by year 2051 than it would be if current levels of educational attainment and fertility rates remain constant in India. Reducing unwanted fertility and improving education will also affect population composition. Fertility reduction due to family planning services and education investment will change population age structure, increasing the proportion of population of labor force age and resulting in a demographic windows opportunity in the next decades, which provides India with the potential for rapid economic growth and even economic takeoff. While both expanding family planning services and education investment will contribute to a larger share of the population of labor force age, the more rapid and immediate fertility reduction due to family planning expansion will generate more significant 


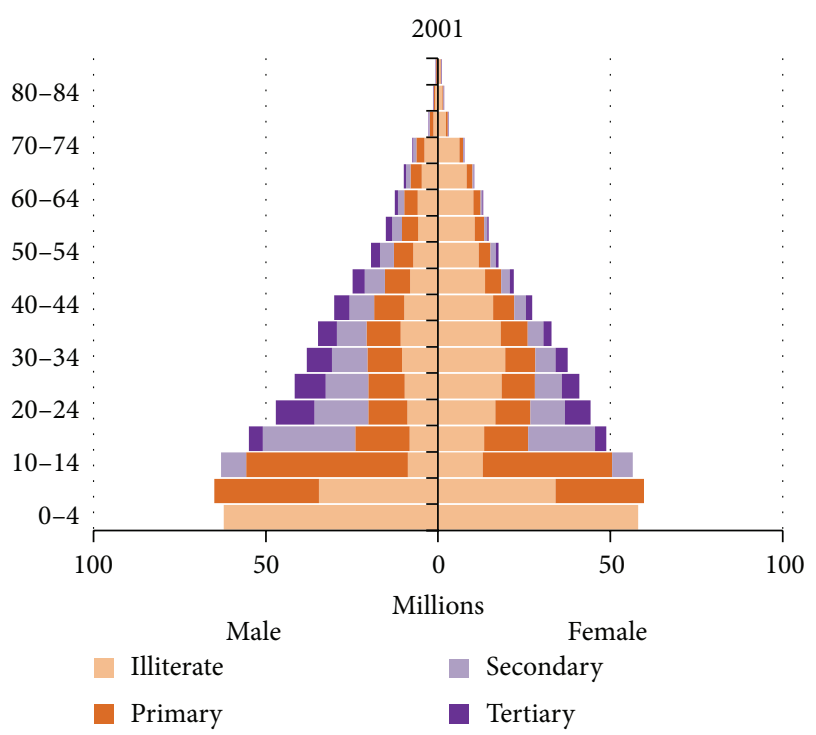

(a)

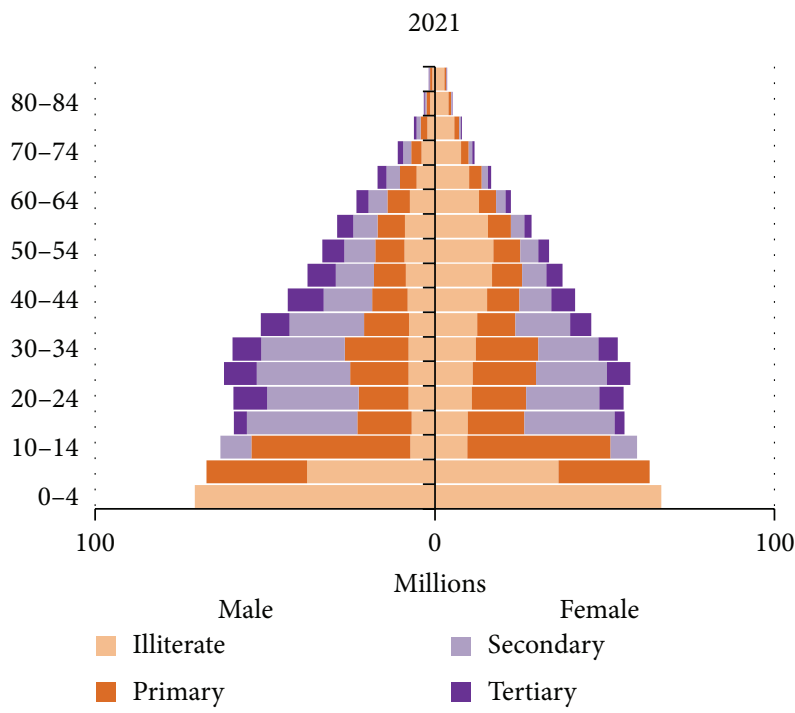

(b)

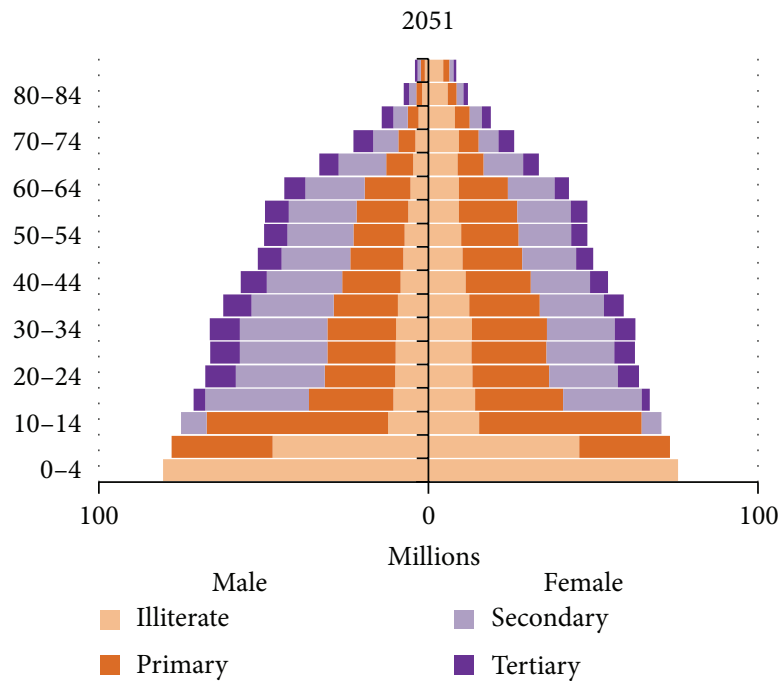

(c)

FIgURE 5: Changes in Indian population composition under Constant Scenario.

impacts on the changes in population age structure and the effects of demographic dividend.

Moreover, a larger share of the population of labor force age alone does not necessarily guarantee an economic miracle. According to the findings of existing researches, it is the larger and more skilled labor force providing increasing human capital that entails rapid economic growth. Our analysis reveals that an increasing education transition rate in India will not only help to achieve a population age structure that is favorable for economic growth, but will also result in a larger share of skilled labor force that help to achieve higher economic growth rate. More importantly, investment in girls' education and achieving gender equality in education will be the most effective measure to increase India's population education level and improve its overall values of human capital.
Is education the best contraceptive? This analysis shows that increasing levels of education among girls is critical and so is increasing access to the means to achieve desired family size, so that women can both gain education and meet their fertility desires. Freedman [32], in a review of the effects of family planning programs on fertility preferences, found that "at their beginnings, the immediate task for programs was not to decrease fertility preferences, but rather to legitimate contraception and make it available as the solution to preexisting problems of unmet need." Women in India of all educational levels are still having more children than they desire. Further education will help reduce the gap between wanted and unwanted fertility, but education needs to be accompanied by increased access by women to the means to control their own fertility and a reduction in barriers placed in their way to using contraception. The family planning program still has an important role to play. 


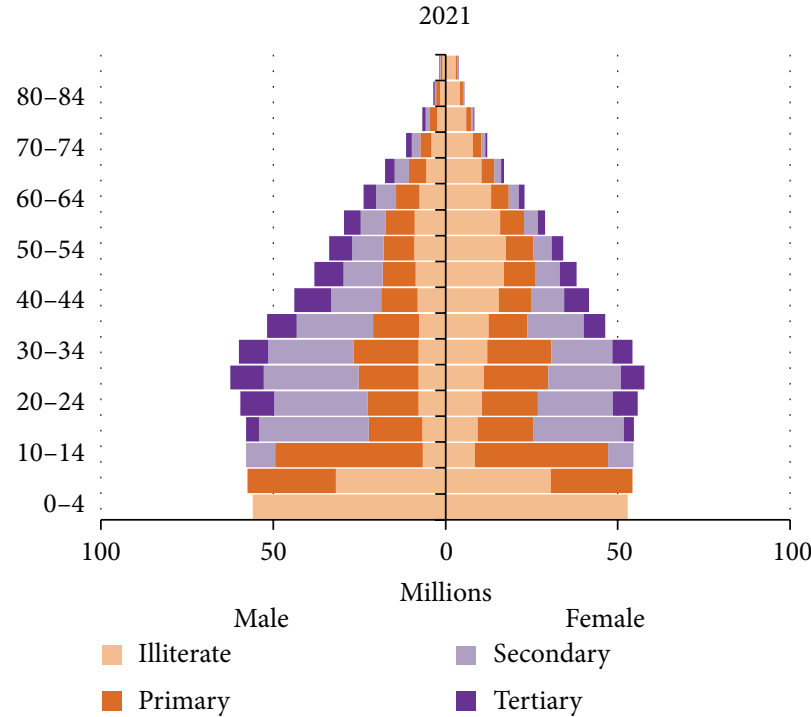

(a)

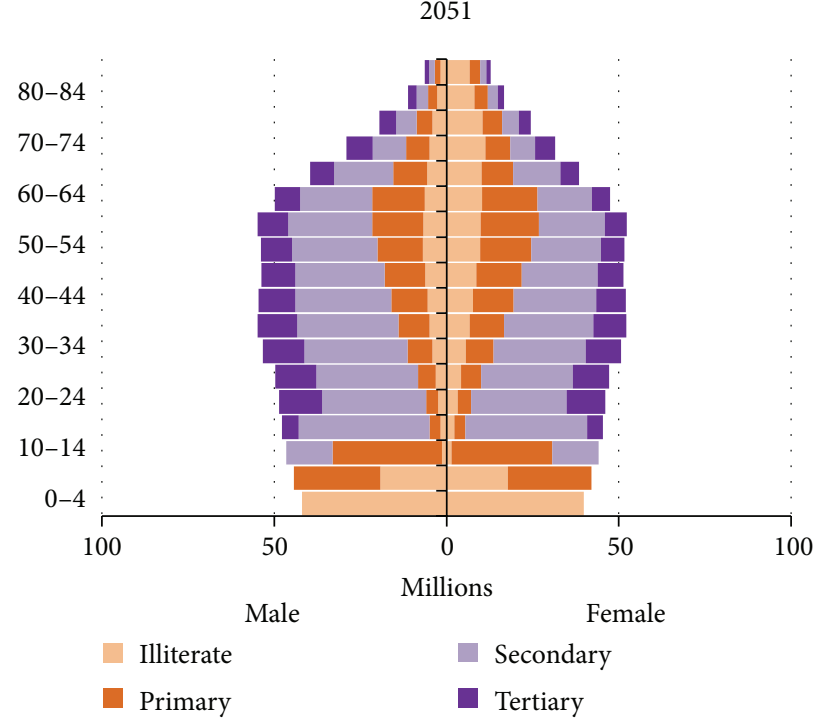

(b)

FIGURE 6: Changes in Indian population composition under RTFR-GET scenario.

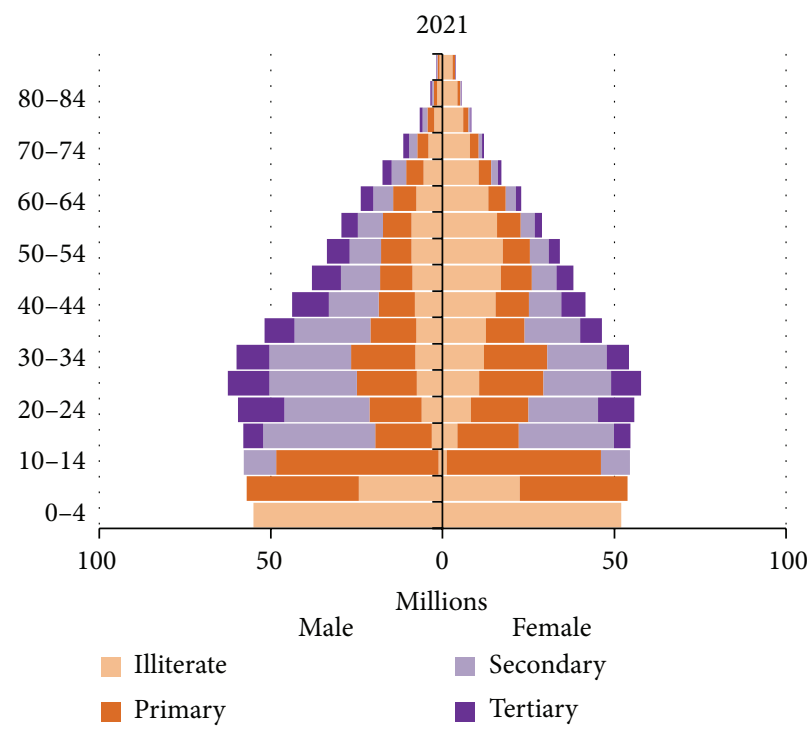

(a)

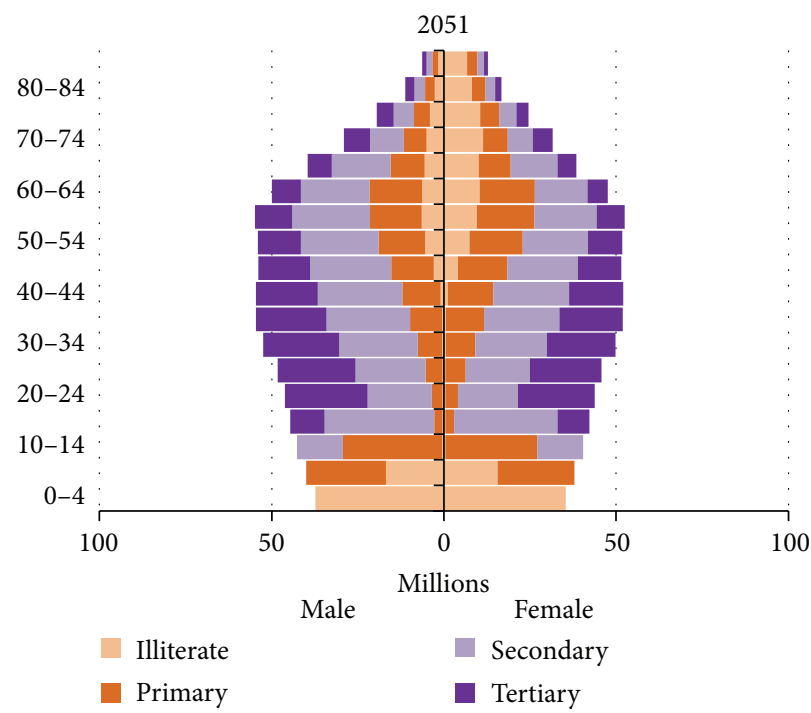

(b)

FIGURE 7: Changes in Indian population composition under RTFR-FT Scenario.

\section{Conflict of Interests}

The authors declare that there is no conflict of interests regarding the publication of this paper.

\section{References}

[1] E. Hannum and C. Buchman, The Consequences of Global Educational Expansion, American Academy of Arts and Sciences, Washington, DC, USA, 2003.

[2] J. E. Cohen, D. E. Bloom, and M. Malin, Educating All Children: A Global Agenda, MIT Press, Cambridge, Mass, USA, 2006.
[3] M. A. Rehani, Keeping the Promise: Five Benefits of Girls Secondary Education, Academy for Educational Development, Washington, DC, USA, 2006.

[4] W. Lutz, J. C. Cuaresma, and W. Sanderson, "Economics: the demography of educational attainment and economic growth," Science, vol. 319, no. 5866, pp. 1047-1048, 2008.

[5] W. Lutz, A. Guojon, and A. Wils, "The population dynamics of human capital accumulation," in Population Aging, Human Capital Accumulation, and Productivity Growth. Supplement to Population and Development Review, A. Prskawetz, D. E. Bloom, and W. Lutz, Eds., vol. 34, Population Council, New York, NY, USA, 2008. 
[6] R. C. Lesthaeghe, C. Vanderhoeft, S. Becker, and M. Kibet, "Individual and contextual effects of education on proximate fertility determinants and on life-time fertility in Kenya," in The Collection and Analysis of Community Data, J. B. Casterline, Ed., pp. 31-63, International Statistical Institute, Voorburg, The Netherlands, 1985.

[7] A. Jain and M. Nag, "Importance of female primary education for fertility reduction in India," Economic and Political Weekly, vol. 21, no. 36, pp. 1602-1608, 1986.

[8] S. J. Jejeebhoy, Women's Education, Autonomy, and Reproductive Behaviour: Experience from Developing Countries, Clarendon Press, Oxford, UK, 1995.

[9] T. C. Martin, "Women's education and fertility: results from 26 demographic and health surveys," Studies in Family Planning, vol. 26, no. 4, pp. 187-202, 1995.

[10] I. Diamond, M. Newby, and S. Varle, "Female education and fertility: examining the links," in Critical Perspectives on Schooling and Fertility in the Developing World, J. Bledsoe, J. Casterline, J. Johnson-Kuhn, and J. Haaga, Eds., vol. 1999, pp. 23-45, National Academy of Sciences Press, Washington, DC, USA.

[11] J. Bongaarts, "Completing the fertility transition in the developing world: the role of educational differences and fertility preferences," Population Studies, vol. 57, no. 3, pp. 321-336, 2003.

[12] S. Rutstein, "Fertility levels, trends and differentials: 19951999," Demographic and Health Surveys Comparative Studies 3, Macro International, Calverton, Md, USA, 2003.

[13] C. B. Lloyd, C. E. Kaufman, and P. Hewett, "The spread of primary schooling in sub-Saharan Africa: implications for fertility change," Population and Development Review, vol. 26, no. 3, pp. 483-515, 2000.

[14] S. H. Cochrane, Fertility and Education. What Do We Really Know? Johns Hopkins University Press, Baltimore, Md, USA, 1979.

[15] A. I. Hermalin and W. M. Mason, "A strategy for the comparative analysis of WFS data, with illustrative examples," in The United Nations Programme for Comparative Analysis of World Fertility Survey Data, pp. 90-168, UNFPA, New York, NY, USA, 1980.

[16] D. Carr, "Is education the best contraceptive?" MEASURE Communication Policy Brief, Population Reference Bureau, Washington, DC, USA, 2000.

[17] J. Drèze and M. Murthi, "Fertility, education, and development: evidence from India," Population and Development Review, vol. 27, no. 1, pp. 33-63, 2001.

[18] A. Moursund and $\varnothing$. Kravdal, "Individual and community effects of women's education and autonomy on contraceptive use in India," Population Studies, vol. 57, no. 3, pp. 285-301, 2003.

[19] W. G. Axinn and J. S. Barber, "Mass education and fertility transition," The American Sociological Review, vol. 66, no. 4, pp. 481-505, 2001.

[20] J. C. Caldwell, P. H. Reddy, and P. Caldwell, "Educational transition in rural south India," Population \& Development Review, vol. 11, no. 1, pp. 29-51, 1985.

[21] H. Presser and G. Sen, Women's Empowerment and Demographic Processes: Moving Beyond Cairo, Oxford University Press, Oxford, UK, 2000.

[22] B. Barnett and J. Stein, Women's Voices Women's Lives, Family Health International, Research Triangle Park, NC, USA, 1998.

[23] W. Lutz and S. Scherbov, "Probabilistic population projections for India with explicit consideration of the education-fertility link," International Statistical Review, vol. 72, no. 1, pp. 81-92, 2004.

[24] W. Lutz, A. Goujon, K. C. Samir, and W. Sanderson, "Reconstruction of populations by age, sex and level of educational attainment for 120 countries for 1970-2000," Vienna Yearbook of Population Research, pp. 193-235, 2007.

[25] W. Lutz, "Measuring human capital," POPNET 40, Winter 2008/09, International Institute for Applied Systems Analysis, 2009.

[26] J. B. Casterline and L. O. El-Zeini, "The estimation of unwanted fertility," Demography, vol. 44, no. 4, pp. 729-745, 2007.

[27] J. Bongaarts, "Population policy options in the developing world," Science, vol. 263, no. 5148, pp. 771-776, 1994.

[28] J. Bongaarts, "Trends in unwanted childbearing in the developing world," Studies in Family Planning, vol. 28, no. 4, pp. 267-277, 1997.

[29] UN, The World Population Prospects 2012 Revision, United Nations, New York, NY, USA, 2013.

[30] D. Bloom, D. Canning, and J. Sevilla, "The Demographic Dividend: A New Perspective on the Economic Consequences of Population Change," Rand Corporation, 2003.

[31] R. Lee and A. Mason, "What is the demographic dividend?" Finance and Development, vol. 43, no. 3, pp. 16-17, 2006.

[32] R. Freedman, "Do family planning programs affect fertility preferences? A literature review," Studies in Family Planning, vol. 28, no. 1, pp. 1-13, 1997. 

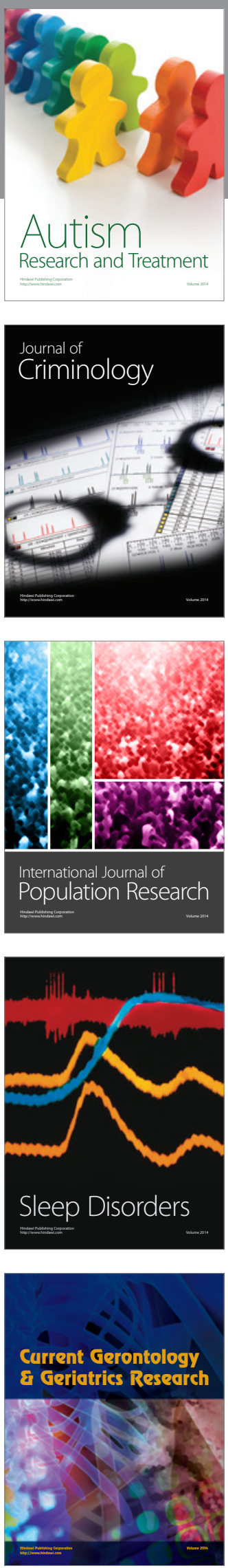
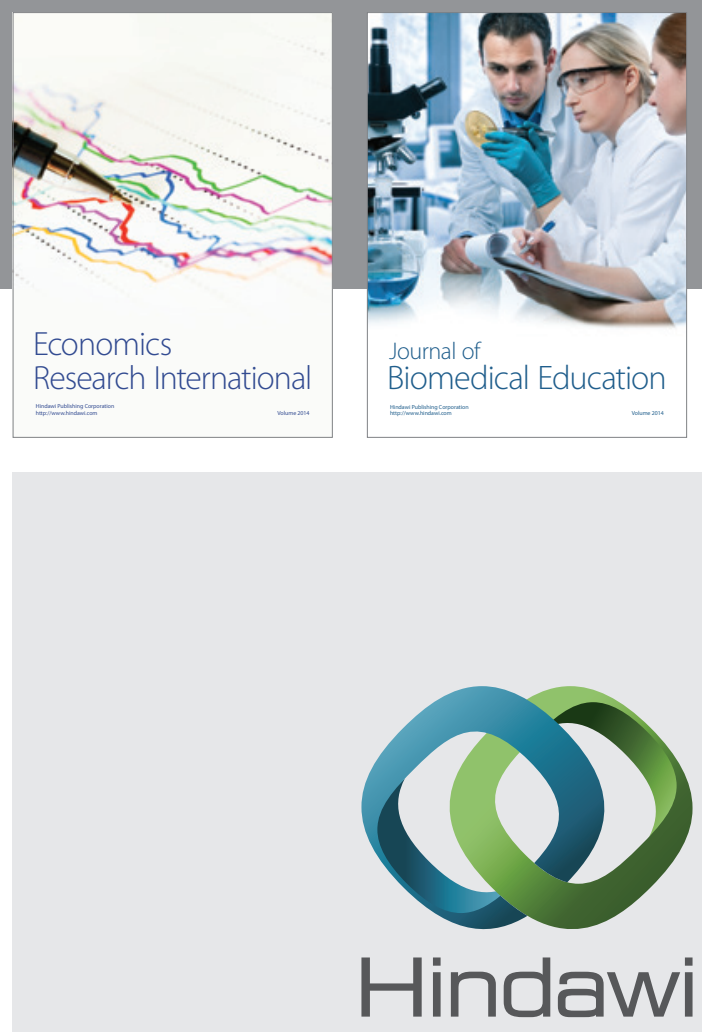

Submit your manuscripts at

http://www.hindawi.com
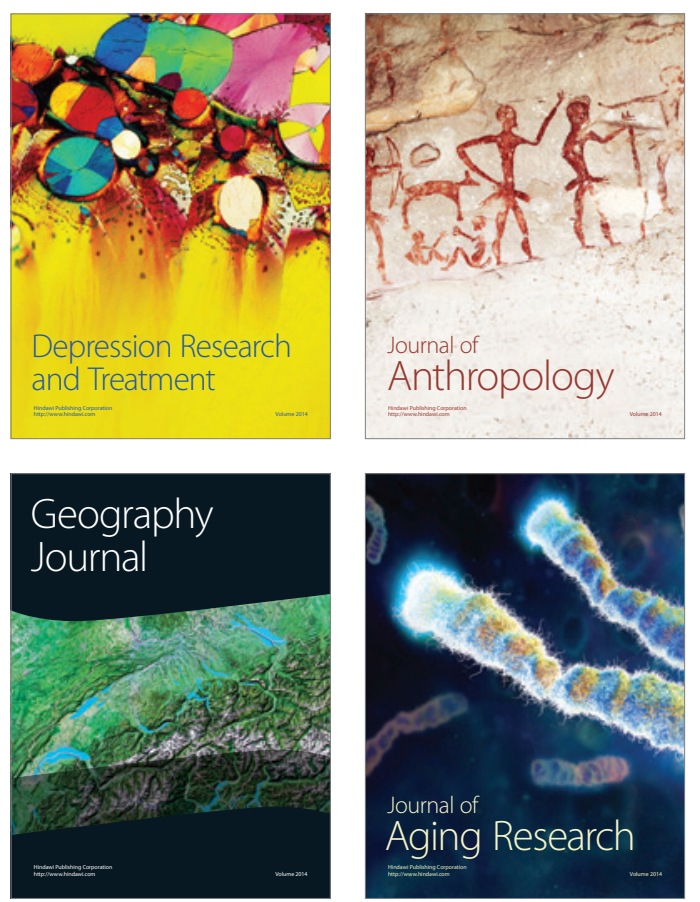
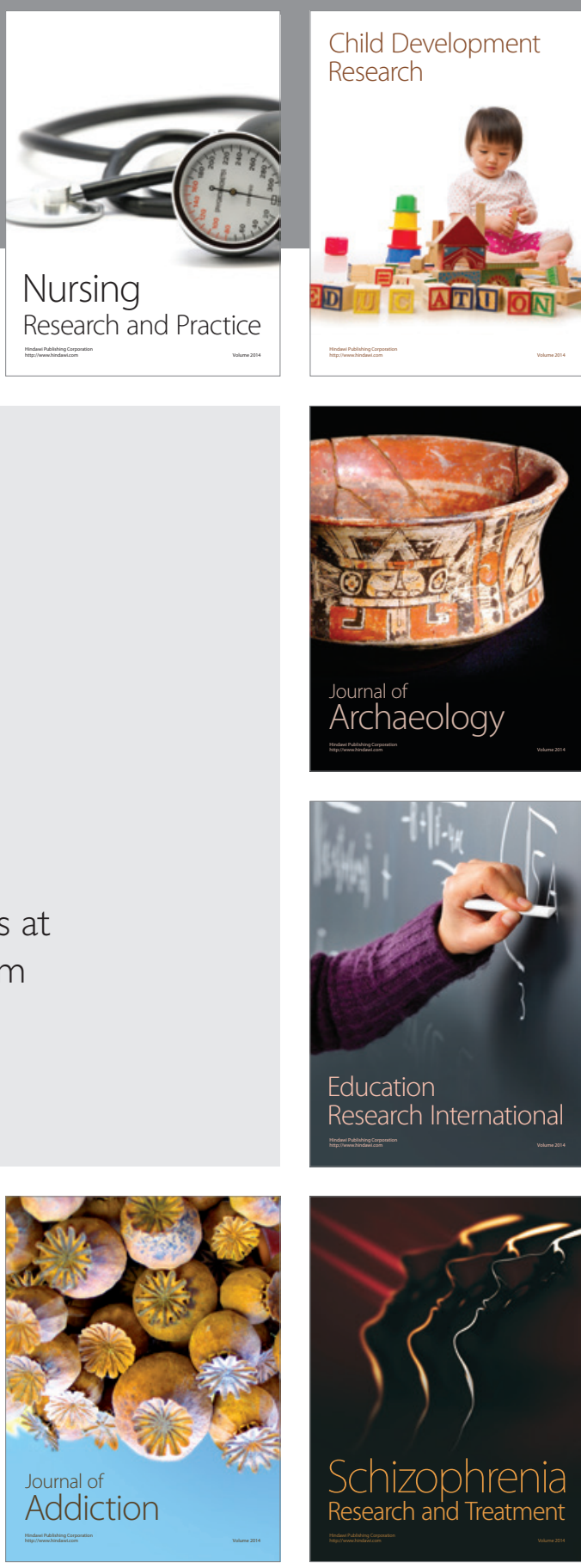

(D)
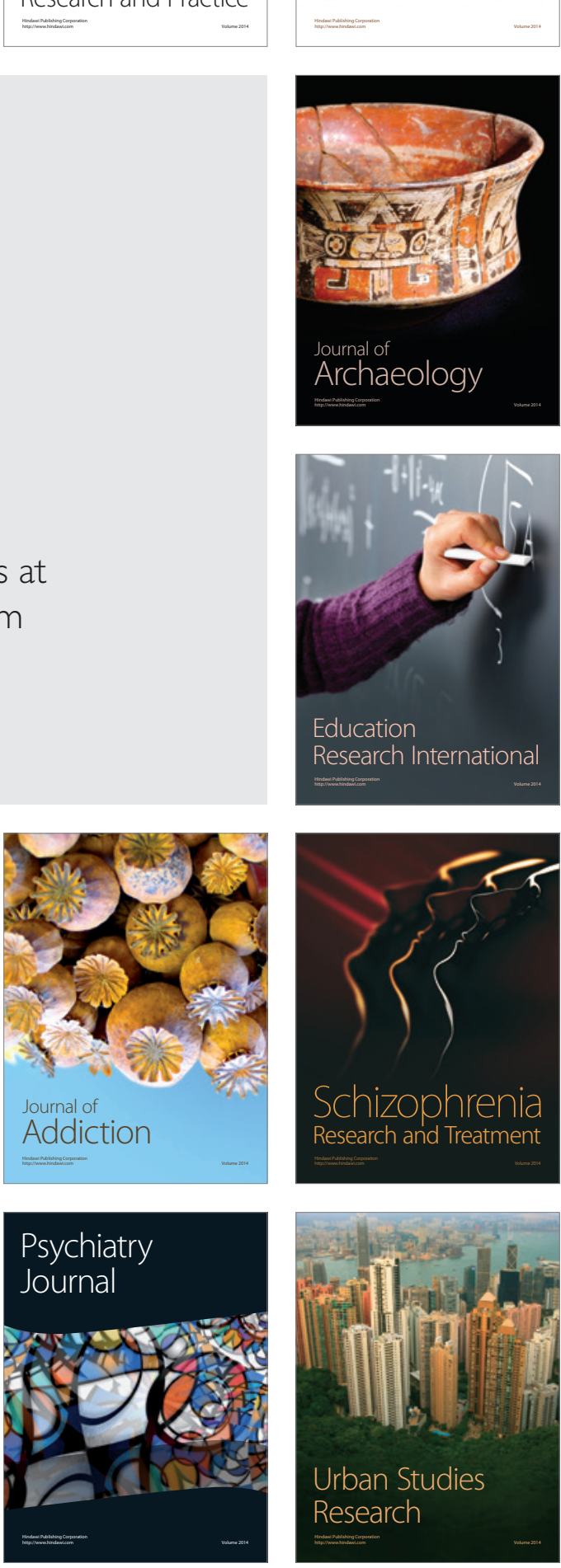